Pesq. Vet. Bras. 36(6):461-467, junho 2016 DOI: $10.1590 / \mathrm{S} 0100-736 \mathrm{X} 2016000600001$

\title{
Arcabouço de PRP-gel associado a células tronco mesenquimais: uso em lesões condrais em modelo experimental equino ${ }^{1}$
}

\author{
Ana Lúcia M. Yamada ${ }^{2}$, Marina L. Alvarenga ${ }^{3}$, Jaqueline S. Brandão ${ }^{3}$, Marcos J. \\ Watanabe ${ }^{4}$, Celso A. Rodrigues ${ }^{4}$, Carlos A. Hussni ${ }^{4}$ e Ana L.G. Alves ${ }^{4 *}$
}

\begin{abstract}
Yamada A.L.M., Alvarenga M.L., Brandão J.S., Watanabe M.J., Rodrigues C.A., Hussni C.A. \& Alves A.L.G. 2016. [PRP-gel scaffold associated with mesenchymal stem cells: use in experimental chondral defect of equine models.] Arcabouço de PRP-gel associado a células tronco mesenquimais: uso em lesões condrais em modelo experimental equino. Pesquisa Veterinária Brasileira 36(6):461-467. Departamento de Cirurgia e Anestesiologia Veterinária, Faculdade de Medicina Veterinária e Zootecnia, Universidade Estadual Paulista, Distrito de Rubião Júnior s/n, Botucatu, SP 18618-970, Brazil. E-mail: anaalves@fmvz.unesp.br

The platelet-rich plasma (PRP) is characterized by its anabolic, anti-inflammatory and gelling capability. Nowadays, the PRP is considered effective in the repair of cartilage defects, and its gelling capability is proper to filling chondral defects. So, the aim of this study was to investigate the use of activated PRP as a fibrin gel scaffold, such as support for the use with mesenchymal stem cells (MSC), on the treatment of experimentally chondral articular defects. Twelve horses were subjected to an arthroscopic surgery at time zero of the experiment (T0). A chondral defect of $15 \mathrm{~mm}$ diameter was created on the medial femoral trochlea and these 12 joints were divided into two groups each with six joints in each group (GA and GB). The joints of the GA were treated with implantation of MSC and PRP-gel. GB joints were the control group. MSCs were cultivated from adipose tissue and PRP-gel was obtained by double centrifugation protocol followed by addition of lyophilized thrombin. After five months (T150) was performed new arthroscopy for macroscopic evaluation of the defect local, collect samples of tissue repair for electron microscopy assessment and also was implemented a magnetic resonance images and computed tomography on GA. It was observed that the PRP-gel associated with CTMs showed a suitable treatment of experimental chondral defects in horses. GA showed a better macroscopic and microscopic appearance of the tissue repair. GB showed smaller number of chondrocytes and increased collagen fibers disorganization. At the magnetic resonance and computed tomography imaging only the local of chondral defect was viewed. The PRP-gel scaffold was satisfactory to use and support MSCs implantation. It showed an easy handling and it was effective, showing a promising results in the repair of induced chondral defects.
\end{abstract}

INDEX TERMS: PRP-gel, mesenchymal stem cells, equine, fibrin gel, platelet-rich plasma, scaffold, stem cells.

RESUMO.- O plasma rico em plaquetas (PRP) é conhecido por apresentar propriedades anabólicas, anti-inflamatórias e capacidade de gelificação. Atualmente o PRP é considera-

\footnotetext{
${ }^{1}$ Recebido em 15 de maio de 2015.

Aceito para publicação em 8 de março de 2016

${ }^{2}$ Doutoranda do Departamento de Cirurgia e Anestesiologia Veterinária, Faculdade de Medicina Veterinária e Zootecnia, Universidade Estadual Paulista (Unesp), Distrito de Rubião Júnior s/n, Botucatu, SP 18618-9070, Brasil.E-mail: miagridi@hotmail.com

${ }^{3}$ Mestranda do Departamento de Cirurgia e Anestesiologia Veterinária, Faculdade de Medicina Veterinária e Zootecnia, Universidade Estadual
}

do eficaz na reparação da cartilagem, sendo sua capacidade de formação de gel indicada para o preenchimento de defeitos condrais. 0 objetivo desse estudo foi analisar o uso do

Paulista (Unesp), Distrito de Rubião Júnior s/n, Botucatu, SP 18618-9070. E-mails: marina@fmvz.unesp.br, jaquelinabrandao.s@hotmail.com

${ }^{4}$ Docentes do Departamento de Cirurgia e Anestesiologia Veterinária, Faculdade de Medicina Veterinária e Zootecnia, Universidade Estadual Paulista (Unesp), Distrito de Rubião Júnior s/n, Botucatu, SP 186189070, Brasil. E-mails: watanabe@fmvz.unesp.br, rodriguesca@fmvz. unesp.br, cahussni@fmvz.unesp.br; *Autor para correspondência: anaalves@fmvz.unesp.br 
PRP ativado, no formato de arcabouço, como suporte para o implante de células tronco mesenquimais (CTM), no preenchimento e tratamento de lesões condrais induzidas em equinos. Doze equinos foram submetidos a uma cirurgia artroscópica no tempo zero do experimento (T0), onde foi induzida uma lesão condral de $15 \mathrm{~mm}$ de diâmetro na tróclea medial femoral dos membros pélvicos direito. As 12 articulações foram divididas em dois grupos distintos com seis articulações cada (GA e GB). As articulações do GA foram submetidas ao tratamento com o implante de CTM em gel de PRP. As articulações de GB foram o grupo controle do experimento. As CTMs foram extraídas do tecido adiposo e o PRP em gel foi obtido por protocolo de dupla centrifugação seguido da adição de trombina liofilizada. Após cinco meses (T150) foi realizada nova artroscopia para avaliação macroscópica do local, coleta de amostras do tecido de reparação para análises de microscopia eletrônica, sendo realizadas imagens ressonância magnética e tomografia computadorizada no local do implante no GA. Observamos que o gel de PRP associado às CTM demonstrou ser adequado no tratamento de defeitos condrais experimentais dos equinos. GA evidenciou um melhor aspecto macroscópico e microscópico do tecido de reparação, sendo que GB mostrou maior desorganização das fibras colágenas. Nas imagens de ressonância magnética e tomografia computadorizada apenas foi relevante o local da lesão condral. 0 arcabouço de gel de PRP demonstrou ser apropriado no suporte do tratamento com as CTMs, sendo de fácil aplicação e efetivo, demonstrando resultados promissores na reparação de lesões condrais induzidas.

TERMOS DE INDEXAÇÃO: PRP-gel, células tronco mesenquimais, arcabouço, cavalo, células-tronco, gel de fibrina, plasma rico em plaquetas.

\section{INTRODUÇÃO}

O plasma rico em plaquetas (PRP) é um concentrado autólogo de fatores de crescimento, mediadores inflamatórios e fibrinogênio. Tendo em vista sua composição, esse produto apresenta efeitos anabólicos, propriedade anti-inflamatória e capacidade de gelificação. Devido à suas características, atualmente o PRP é considerado potencialmente eficaz na reparação da cartilagem e suas propriedades são requeridas e indicadas no tratamento de defeitos condrais (Xie et al. 2014). Os fatores de crescimento e as diversas proteínas bioativas presentes no PRP são capazes de estimular de forma consistente a migração e proliferação celular, estimular a produção de matriz extracelular e reduzir o ciclo inflamatório articular induzido principalmente pela IL-1 (Pichereau et al. 2014, Xie et al. 2014).

As plaquetas presentes no PRP contêm os grânulos- $\alpha$, que são unidades de armazenamento. Essas unidades transportam os fatores de crescimento em uma forma inativa, além de uma molécula chamada fibronectina e outras proteínas plasmáticas, que facilitam a adesão celular, a reparação de tecidos conectivos e contribuem no processo de osteointegração e osteoindução. A maior parte dos fatores de crescimento é ativada durante ou logo após o processo inflamatório, e atuam principalmente sobre a mitose, secreção e migração celular (Jain et al. 2012, Xie et al. 2014).
Devido à presença do fibrinogênio, que é prontamente transformado em fibrina após a ativação, e consequente competência de gelificação, o PRP é capaz de formar um arcabouço de três dimensões, fornecendo substrato para o implante celular conjunto (Lee et al. 2013, Xie et al. 2014). Estudos recentes revelam que o arcabouço de PRP é dividido em diferentes zonas, sendo elas a zona de plaquetas, fibrina e células, quando aplicadas conjuntamente. (Xie et al. 2012, Xie et al. 2014, Textor et al. 2014). 0 gel de PRP possui uma estrutura semelhante a um favo de mel, e permitem uma distribuição uniforme de plaquetas e células quando homogeneizados ainda na forma líquida, anterior a gelificação (Xie et al. 2012).

As plaquetas liberam gradativamente os fatores de crescimento, estimulando diversos tipos celulares, como condrócitos e as CTMs, promovendo proliferação, síntese de agrecan e colágeno tipo II. 0 formato tridimensional do gel resultante da ativação do fibrinogênio presente no PRP pode prevenir a apoptose celular e inibir os efeitos catabólicos de algumas citocinas próinflamatórias e metaloproteinases (Yamada 2011, Xie et al. 2014). 0 tempo de permanência desse arcabouço de PRP, formado pelo gel de fibrina, é variável segundo a literatura, podendo durar de 7 a 15 dias (Yamada 2011, Xie et al. 2014). Ainda, o arcabouço de PRP possui vantagens como: a fácil obtenção, simples aplicação e pouco custo de produção (Yamada et al. 2012), favorecendo o retorno biomecânico da articulação comprometida e reduzindo a dor (Kon et al. 2010, Sun et al. 2010, Yamada 2011, Milano et al. 2010, Xie et al. 2012, Lee et al. 2013).

Portanto, devido às inúmeras qualidades e benefícios apresentados pelo PRP em gel, o objetivo desse estudo foi avaliar a utilização do arcabouço de PRP em gel, como base para a aplicação de células-tronco mesenquimais, em defeitos da cartilagem articular induzidos experimentalmente, observando principalmente a viabilidade de aplicação, a capacidade de fixação e o aspecto da lesão após a instituição do tratamento.

\section{MATERIAL E MÉTODOS}

Este estudo foi aprovado pela Comissão de Ética no Uso de Animais sob protocolo número 225/2011 - CEUA. Foram utilizados 12 equinos, mestiços Crioulos, com 2 a 5 anos de idade, fêmeas e machos castrados, pesando em média $350 \mathrm{~kg}$, hígidos e sem histórico de afecções locomotoras. As doze articulações femoropatelares dos membros pélvicos direito (MPD) desses 12 animais foram abordadas por cirurgia artroscópica para a realização de um defeito condral, e divididas em dois grupos distintos com seis articulações cada (GA e GB). As articulações do GA foram submetidas ao tratamento com o implante de CTM em gel de PRP. As articulações de GB foram o grupo controle do experimento, sem a aplicação de qualquer tipo de tratamento. Esses animais permaneceram em baias na semana anterior e três semanas posteriores aos procedimentos cirúrgicos, sendo soltos em piquetes nos intervalos das cirurgias.

0 primeiro procedimento artroscópico foi considerado como tempo zero (T0) do experimento, sendo abordados todos os animais. A técnica artroscópica utilizada foi a proposta por Mcilwraith (2005). Para criar a lesão foram utilizadas lâminas abrasivas motorizadas (broca circular Razek 2,9/5,5 - Razek Equipamentos, 
Brasil) e pinças artroscópicas, com desgaste controlado, suficiente para obter a dimensão da lesão condral desejada. As lesões foram padronizadas em aproximadamente $15 \mathrm{~mm}$ de diâmetro e induzidas retirando a cartilagem hialina e toda a cartilagem calcificada, porém, não havendo abrasão, perfuração ou sangramento do osso subcondral (Fig.1).

As CTMs foram obtidas e cultivadas a partir do tecido adiposo dos equinos experimentais do GA, coletado 40 dias antes de T0. A extração da fração vascular estromal e o cultivo celular foram realizados segundo técnica descrita para equinos Yamada (2011) e Carvalho et al. (2013). A viabilidade média das células no momento da aplicação foi mensurada através da técnica de Azul de Trypan e a caracterização das CTMs foi realizada antes da aplicação dos tratamentos, pela reação antígeno-anticorpo, por citometria de fluxo e marcadores de superfície segundo Yamada (2011) e Carvalho et al. (2013). Ainda objetivando a caracterização, parte das CTMs obtidas para o tratamento foi submetida às diferenciações, com o uso de "kits" comerciais, em tecido cartilaginoso (STEMPRO Chondrogenesis Differentiation Kit GIBCO - Invitrogen Cell Cuture, EUA), ósseo (STEMPRO Osteogenesis Differentiation Kit GIBCO - Invitrogen Cell Culture, EUA) e adiposo (STEMPRO Adipogenesis Differentiation Kit GIBCO - Invitrogen Cell Cuture, EUA), seguindo as instruções do fabricante. A dose utilizada no tratamento foi de $10^{7}$ células por lesão tratada.

O PRP utilizado no tratamento das lesões foi processado pelo método de centrifugação dupla, com sangue total coletado dos seis animais de GA, em tubo de citrato de sódio a 3,8\% (BD - Brasil), sendo igualmente quantificada a concentração do fator de crescimento IGF-1 no PRP utilizado. Foram testados diversos protocolos para a obtenção do PRP (Quadro 1), sendo a manipulação das amostras detalhadamente realizada a fim de erradicar erros nas contagem das plaquetas, reduzir a agregação e destruição plaquetária. Para isso foram aplicadas diversas manobras laboratoriais, incluindo tempos de descanso, a delicada homogeneização e a manutenção dos tubos que continham as amostras no interior de caixas de isopor, evitando assim a variação de temperatura. As amostras eram retiradas das caixas de isopor apenas para a centrifugação com temperatura controlada a $25^{\circ} \mathrm{C}$. Os tempos de

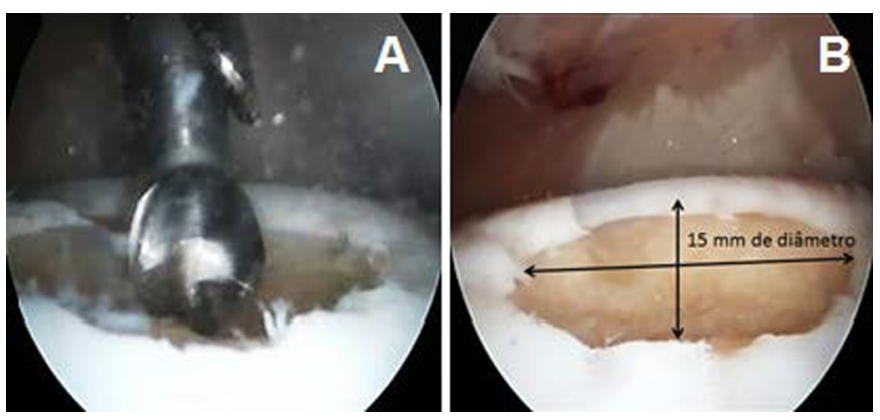

Fig.1. (A) Realização do defeito em T0 com a broca circular retirando apenas a cartilagem hialina. (B) defeito já criado nas mensurações propostas pelo experimento (15mm de diâmetro).

Quadro 1. Protocolos de obtenção do PRP testados durante o experimento, cada protocolo testado foi realizado em três repetições (três amostras)

\begin{tabular}{lcc}
\hline Protocolo testado & Primeira centrifugação & Segunda centrifugação \\
\hline Milano et al. (2010) & $2400 \mathrm{rpm}-3 \mathrm{~min}$ & $3000 \mathrm{rpm}-12 \mathrm{~min}$ \\
Proposto pelo autor & $300 \mathrm{~g}-5 \mathrm{~min}$ & $700 \mathrm{~g}-15 \mathrm{~min}$ \\
Proposto pelo autor & $160 \mathrm{~g}-10 \mathrm{~min}$ & $400 \mathrm{~g}-10 \mathrm{~min}$ \\
Carmona et al. (2009) & $120 \mathrm{~g}-5 \mathrm{~min}$ & $240 \mathrm{~g}-5 \mathrm{~min}$ \\
Vendramin et al. (2006) & $300 \mathrm{~g}-10 \mathrm{~min}$ & $660 \mathrm{~g}-10 \mathrm{~min}$ \\
Proposto pelo autor & $360 \mathrm{~g}-10 \mathrm{~min}$ & $820 \mathrm{~g}-10 \mathrm{~min}$
\end{tabular}

descanso foram fixados em 45 minutos, entre cada centrifugação e cada processamento. A técnica de preparação do gel igualmente foi padronizada. Para alcançar o gel ideal para a aplicação intra-articular e formação do arcabouço foram testadas diferentes concentrações de trombina no PRP previamente preparado $(10 \%$, 15\%, 20\%, 25\%, 30\% e 35\% de trombina liofilizada reconstituída em água estéril/ para cada mililitro de PRP). Foi utilizado $10 \%$ de cloreto de cálcio nas amostras de PRP, objetivando sua ativação. O PRP tinha que apresentar uma contagem igual ou maior que 500.000 plaquetas/ $\mu \mathrm{L}$ para a viabilidade de utilização, que foi verificado por contagem microscópica em câmara de Neubauer espelhada.

O implante intralesional das CTMs associadas ao gel de PRP para as articulações do GA foi realizado no mesmo momento artroscópico de T0; imediatamente após a indução da lesão. Para cada articulação tratada o "pellet" de células tronco mesenquimais autólogas previamente cultivadas foi ressuspenso em $4 \mathrm{~mL}$ de PRP autólogo previamente processado. No momento da aplicação do implante ao leito receptor foi adicionado para cada $1 \mathrm{~mL}$ do composto CTM e PRP (4mL) 10\% de cloreto de cálcio a 10\% (para ativação do PRP) (Sigma-Aldrich - Life Science) e 15\% de trombina bovina reconstituída (Sigma-Aldrich - Life Science - lyophilized powder, 600-2,000 NIH units/mg protein) em água estéril para formação do arcabouço de gel de PRP.

Após cinco meses (T150), foram abordadas novamente todas as articulações dos dois grupos para a avaliação macroscópica do local da lesão e observação do aspecto da reparação. Neste momento também foram coletadas amostras do tecido de reparação na região central do defeito condral de cada lesão dos dois grupos para análises de microscopia eletrônica, pelo método de varredura, no Centro de Microscopia Eletrônica do Instituto de Biociências, Unesp-Botucatu. As articulações de GA foram encaminhadas para exames de ressonância magnética e tomografia computadorizada da articulação femoropatelar do MPD, em T150, para a observação do local onde foi induzida a lesão condral e implantado o arcabouço de PRP em gel associado às CTM.

\section{RESULTADOS}

Em relação às células-tronco, foram aplicadas em média $1,35 \times 10^{7}$ células para cada lesão de GA. A média de viabilidade dessas células foi de 95,61\%. As células apresentaram média de marcação positiva para o CD44 (81,47\%), CD90 (95,72\%) e CD105 (63,15\%), apresentando média de marcação negativa para o MHC Classe II (2,63\%). Todas as células submetidas às diferenciações através dos "kits" comerciais confirmaram a transformação em tecido ósseo, adiposo e cartilaginoso.

Após a realização dos testes de diversos protocolos e no desenvolvimento do gel de PRP foi observado um material consistente, adequado para a aplicação em defeitos condrais e para a formação de um arcabouço 3D. Foi observada que a concentração de $15 \%$ de trombina bovina se revelou a melhor, permitindo a aplicação ainda em formato fluído e ao mesmo tempo, constituindo um arcabouço estável. Concentrações acima de 30\% de adição de trombina bovina não demonstraram diferença na qualidade do gel, provavelmente devido ao consumo total de fibrinogênio, porém resultavam em geleificações muito rápidas, as quais atrapalhavam a aplicação. 0 melhor protocolo testado, sendo o utilizado nesse estudo, foi o proposto pelo autor, consistindo na primeira centrifugação a $300 \mathrm{~g}$ durante 5 min, e a segunda centrifugação a $700 \mathrm{~g}$ durante 15 min, 
seguindo detalhadamente os passos indicados na Figura 2. Foram descartados $75 \%$ do plasma sobrenadante apenas após a segunda centrifugação e desprezada a zona de névoa ("Buffy Coat"). Os resultados médios das concentrações plaquetárias observadas nos diferentes protocolos estão dispostos no Quadro 2. As concentrações plaquetárias e de IGF-1 no PRP utilizado estão no Quadro 3. A média de plaquetas observada foi de 720.478 plaquetas $/ \mu \mathrm{L}$, superando o requisito mínimo de 500.000 plaquetas $/ \mu \mathrm{L}$, não foram observadas diferenças estatisticamente significativas entre

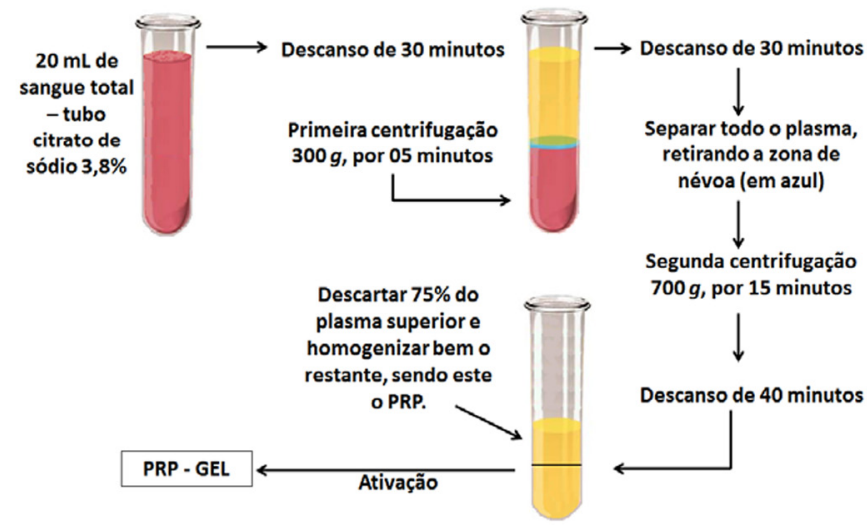

Fig.2. Representação esquemática do protocolo de centrifugação utilizado para a obtenção do PRP.

Quadro 2. Diferentes protocolos testados no estudo, que apresentaram maior concentração média de plaquetas (valores máximos observados)

\begin{tabular}{|c|c|c|}
\hline Protocolo testado & $\begin{array}{l}\text { Valor plaquetário basal } \\
\text { (plaquetas } / \mu \mathrm{L} \text { ) }\end{array}$ & $\begin{array}{l}\text { Valor plaquetário PRP } \\
\text { (plaquetas } / \mu \mathrm{L} \text { ) }\end{array}$ \\
\hline $\begin{array}{l}\text { Milano et al., (2010) } \\
2400 \mathrm{rpm}-3 \mathrm{~min} / \\
3000 \mathrm{rpm}-12 \mathrm{~min}\end{array}$ & 183.000 & 615.670 \\
\hline $\begin{array}{l}\text { Proposto pelo autor, } \\
300 \mathrm{~g}-5 \mathrm{~min} / \\
700 \mathrm{~g}-15 \mathrm{~min}\end{array}$ & 133.000 & 1.166 .550 \\
\hline $\begin{array}{l}\text { Proposto pelo autor } \\
160 \mathrm{~g}-10 \mathrm{~min} / \\
400 \mathrm{~g}-10 \mathrm{mim}\end{array}$ & 212.000 & 598.111 \\
\hline $\begin{array}{l}\text { Carmona et al., (2009) } \\
120 \mathrm{~g}-5 \mathrm{~min} / \\
240 \mathrm{~g}-5 \mathrm{~min}\end{array}$ & 195.000 & 322.250 \\
\hline $\begin{array}{l}\text { Vendramin et al., (2006) } \\
300 \mathrm{~g}-10 \mathrm{~min} / \\
660 \mathrm{~g}-10 \mathrm{~min}\end{array}$ & 195.000 & 436.825 \\
\hline $\begin{array}{l}\text { Proposto pelo autor } \\
360 \mathrm{~g}-10 \mathrm{~min} / \\
820 \mathrm{~g}-10 \mathrm{mim}\end{array}$ & 235.000 & 325.988 \\
\hline
\end{tabular}

Quadro 3. Contagem plaquetária do PRP e quantificação de IGF-1 (em nanogramas/mL) de cada animal do grupo $\mathrm{A}$

\begin{tabular}{lcc}
\hline Grupo A & $\begin{array}{c}\text { Contagem de plaquetas no } \\
\text { PRP (plaquetas } / \mu \mathrm{L})\end{array}$ & $\begin{array}{c}\text { Concentração de IGF-1 no } \\
\text { PRP utilizado }(\mathrm{ng} / \mathrm{mL})\end{array}$ \\
\hline Animal 1 & 698.000 & 134,50 \\
Animal 2 & 711.000 & 169,00 \\
Animal 3 & 670.000 & 179,50 \\
Animal 4 & 873.650 & 150,00 \\
Animal 5 & 681.723 & 188,00 \\
Animal 6 & 688.500 & 178,00 \\
Média & 720.478 & 166,50
\end{tabular}

a concentração plaquetária no PRP entre os diferentes animais (animais 1 ao 6).

Em referência à aplicabilidade, o implante do arcabouço de PRP associado às CTMs demonstrou boa viabilidade de aplicação. Em fase final de gelificação o composto foi colocado sobre a lesão induzida, com o auxílio de uma agulha 30x80, e a distensão articular com $\mathrm{CO}_{2}$ foi mantida até a completa secagem e fixação do gel. Não houve intercorrências em relação à aplicação do gel, porém, a experiência do cirurgião e a exatidão no tempo transcorrido de gelificação foram essenciais no sucesso do implante do arcabouço. A gelificação completa do PRP (formação do coágulo) ocorreu em média em 36 segundos (tempo de trombina) (Fig.3). Na avaliação macroscópica, o GA apresentou um tecido de reparação com melhor aspecto macroscópico, ou seja, um tecido com melhor resistência à palpação com a probe, semelhante à cartilagem, aderido às bordas da lesão e preenchendo a área do defeito condral experimental. 0 GB apresentou falhas de preenchimento, um tecido muito friável e pouco aderido. Em T150, não havia resquícios do

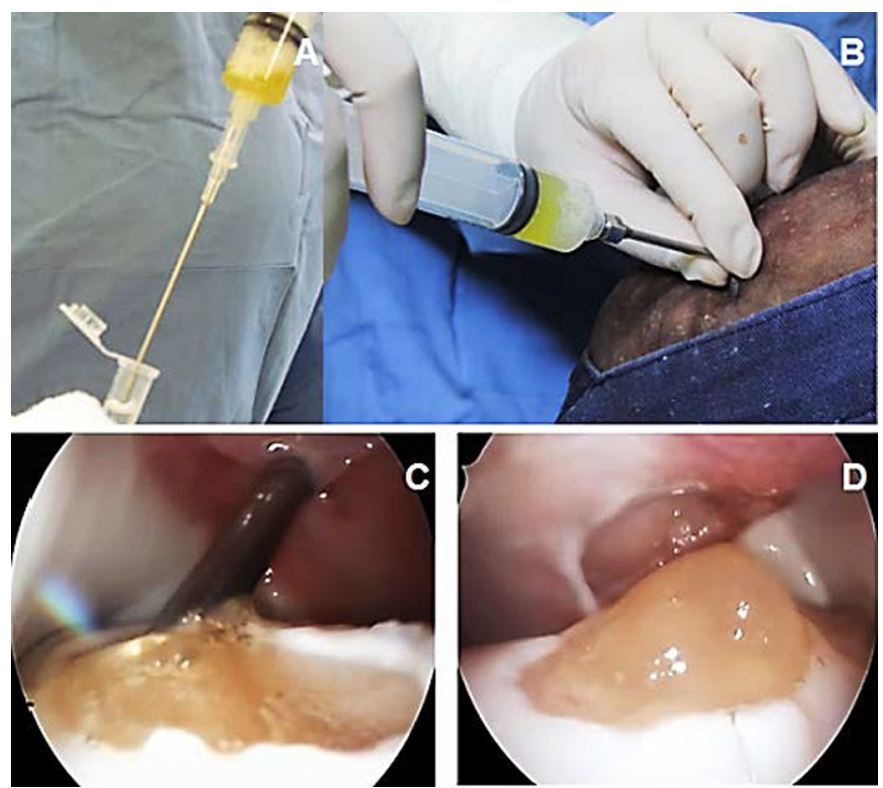

Fig.3. Implante do arcabouço de PRP associado às CTM em T150. (A) Aspiração do composto, (B,C) aplicação em fase de gelificação, (D) secagem final do arcabouço no leito receptor.

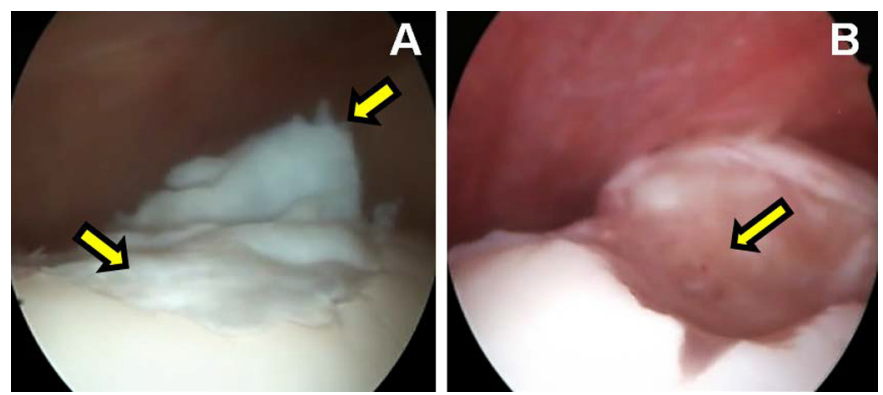

Fig.4. Tecido de reparação observado em T150. (A) 0 GA apresentou um tecido de reparação com melhor aspecto macroscópico, liso, semelhante à cartilagem (setas) (B) 0 GB apresentou graves falhas de preenchimento, um tecido muito friável e pouco aderido (seta). 
arcabouço em gel em nenhuma das articulações, apenas foi observado o tecido de reparação (Fig.4).

Ao final do experimento, em T150, um dos animais do GA precisou ser submetido à eutanásia devido a alterações não relacionadas ao experimento (uma fratura acidental de fêmur). Foram obtidas as partes anatômicas do cadáver (tróclea femoral do MPD), onde foi realizado o estudo (tratamento do GA), sendo possível observar o tecido de reparação formado após o implante do arcabouço (Fig.5).

Nas imagens de microscopia eletrônica de varredura em T150, observamos no GA a superfície irregular, pouca celularidade e exposição de fibras colágenas através de falhas da matriz condral, com a presença de fibras mais finas e parcialmente organizadas. No GB, observamos as fibras colágenas completamente expostas, com pouca presença de cartilagem integra e nenhuma matriz condral ou células, as fibras colágenas se apresentaram mais densas e com maior desorganização em relação à orientação própria do tecido cartilaginoso (Fig.6). Nas imagens de ressonância e

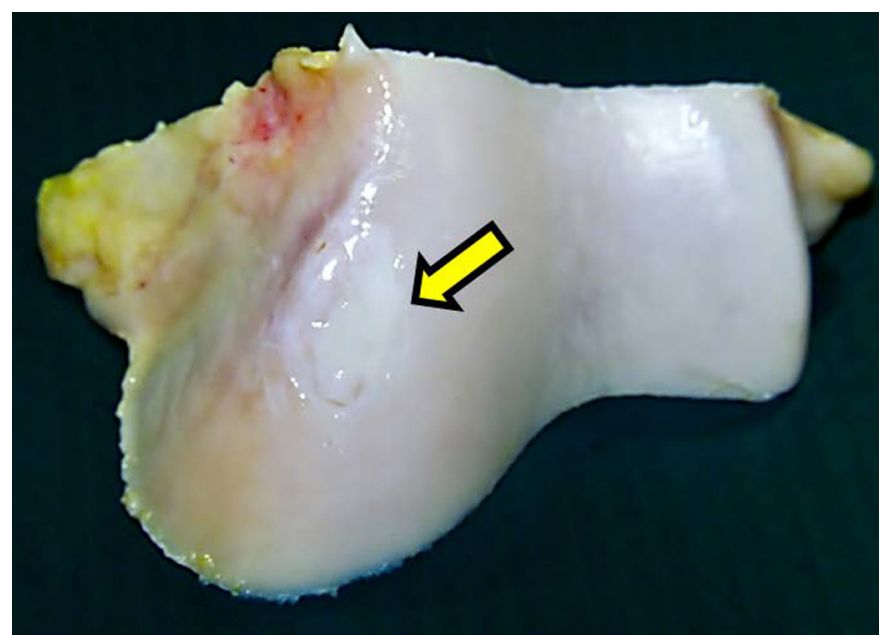

Fig.5. Tecido de reparação observado em T150 no GA (animal tratado com CTM em gel de PRP) na peça após eutanásia do animal. 0 tecido de reparação preenchendo completamente a lesão, branco e liso (seta).

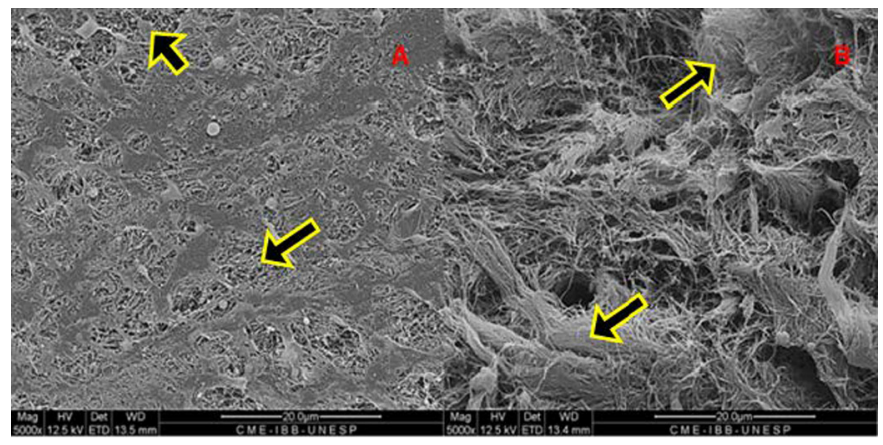

Fig.6. (A) Imagens de microscopia eletrônica de varredura em T150. Superfície irregular, pouca celularidade e exposição de fibras colágenas através de falhas da matriz condral (setas), com a presença de fibras mais finas e parcialmente organizadas no GA. (B) Fibras colágenas completamente expostas, sem a presença de cartilagem integra e nenhuma matriz condral ou células, as fibras colágenas se apresentaram mais densas (setas) e com maior desorganização no GB. Magnitude 5000x.

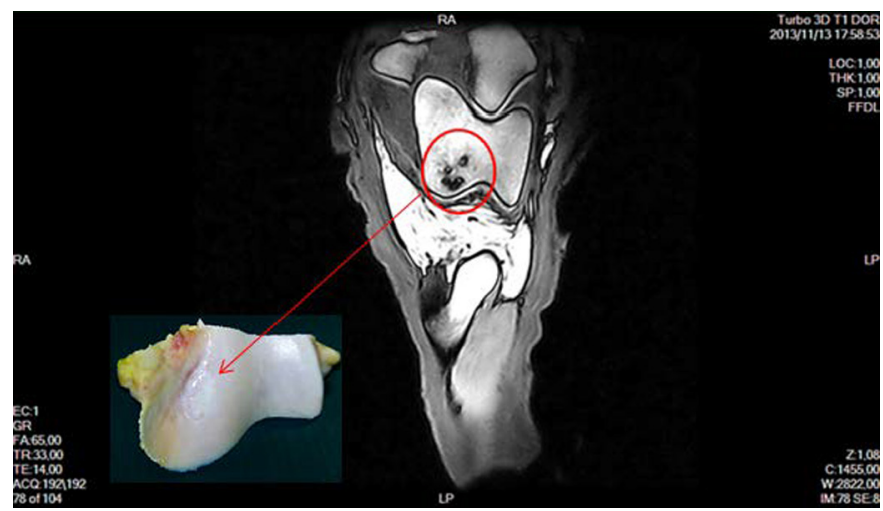

Fig.7. Local onde foi induzido o defeito condral na tróclea femoral do GA (círculo) em T150 nas imagens de ressonância magnética. Não há imagens formadas por sinais do tecido de reparação ou resquícios do arcabouço implantado.

tomografia não foi possível observar a presença do gel ou do tecido de reparação em GA, apenas o local onde foi realizada a lesão condral (Fig.7).

\section{DISCUSSÃo}

Um bioarcabouço precisa apresentar algumas características básicas para atuar adequadamente, como ser biocompatível e atuar de forma positiva no processo de reparação. Deve igualmente definir e ocupar um espaço no qual irá atuar durante a cicatrização, mimetizando temporariamente a função do tecido no qual foi implantado, permitindo igualmente a inclusão de células, moléculas, vetores, entre outros. Por fim, é importante que apresente uma composição química, porosidade, superfície e formato que permitam a migração e proliferação celular, além da neovascularização (Kon et al. 2013). Sugerimos que a associação de CTMs em gel de PRP, utilizada no preenchimento das lesões condrais induzidas, enquadrou-se nessas características básicas relatadas.

O PRP cumpriu a maior parte desses pré-requisitos, se tornando um material promissor na reparação da cartilagem articular e formação de arcabouços. O PRP, além de fornecer uma matriz de fibrina que serve de suporte tridimensional para o crescimento de células, é uma solução rica em fatores de crescimento. Sua simplicidade de preparação e complexidade de composição faz com que este bioproduto contribua significativamente para a regeneração tecidual. Lee et al. (2013), referiram que os arcabouços tridimensionais fornecem um microambiente adequado para a indução e manutenção do fenótipo condrogênico, observado no nosso estudo pela melhor apresentação macroscópica e microscópica do GA. Além disso, como observado durante o implante do gel de PRP nessa experimentação, o material fluido, sendo o PRP em fase final de gelificação, foi facilmente aplicado sobre o leito receptor, podendo incorporar as células-tronco sem qualquer intercorrências durante a formação do arcabouço.

Nesse estudo, o arcabouço foi produzido a partir da polimerização da fibrina presente no PRP. Esse tipo de estrutura biocompatível foi capaz de fixar as CTMs no local da lesão, proporcionando um microambiente protetor e rico 
em fatores de crescimento. Dentro do arcabouço de PRP as CTMs migram e se desenvolvem podendo exercer seu efeito biológico, auxiliando de forma inegável no processo de reparação condral (Yamada et al. 2013). Corroborando com este trabalho, Zhu et al. (2013) relataram que o arcabouço de PRP estimulou a migração, a adesão e a proliferação das CTMs, resultando em um aumento da diferenciação condrogênica, o que consequentemente estimulou os condrócitos a produzirem glicosaminoglicanos, melhorando o aspecto macroscópico do tecido. Estas características teciduais também foram observadas no GA, sendo provavelmente relacionado aos efeitos biológicos das CTMs e aos fatores de crescimento presentes no PRP. O PRP igualmente favorece o contato entre as células, estimulando a liberação de adesina, molécula indispensável na interação célula-arcabouço e célula-célula, influenciando no sucesso do tratamento (Beitzel et al. 2014).

Os diferentes protocolos testados, principalmente em relação à concentração de trombina, são essenciais no "bom desempenho" do plasma rico em plaquetas. 0 protocolo utilizado nesse trabalho objetivou maximizar a eficiência desse composto autólogo. Textor et al. (2011) relataram que o PRP aplicado sem a ativação, ou de forma isolada, tem uma diminuta liberação de fatores de crescimento. Mesmo em contato com o colágeno no local inflamado, a concentração de fatores de crescimento liberada corresponde apenas a $10 \%$ do total plaquetário. Sendo assim, um adequado protocolo de ativação deve ser instituído, sendo a trombina bovina utilizada para a formação do coágulo de fibrina na obtenção do gel e o cloreto de cálcio para a ativação plaquetária, uma vez que o cloreto de cálcio se mostra mais eficiente quando comparado à outros métodos de ativação (Yamada 2011, Textor \& Tablin 2012)

A diferença observada na avaliação macroscópica e microscópica entre os grupos, indicando um tecido de reparação com superior produção de matriz extracelular e mais semelhante à cartilagem articular observado no GA foi condizente com os relatos da literatura atual (Yamada 2011, Xie et al. 2012, Textor \& Tablin 2013, Lee et al. 2013). O PRP é eficaz na reparação da cartilagem, promovendo a proliferação celular, principalmente de condrócitos, e consequentemente estimulando a síntese de matriz extracelular, como proteoglicanos e colágeno tipo II (Krüger et al. 2012, Tsuzuki et al. 2013). Lesões condrais experimentalmente induzidas em equinos, e tratadas com a associação CTM em gel de PRP, demonstraram melhor organização tecidual, maior número de condrócitos, maior produção de matriz extracelular e menor produção de fibrose quando comparadas a um grupo controle sem tratamento (Yamada 2011). Tal fato pôde ser observado no GA nas imagens de microscopia eletrônica. 0 GA apresentou maior organização das fibras colágenas, com fibras menos densas, indicando maior produção de colágeno tipo II e menor proporção de fibrocartilagem, além disso, no GA, pode-se notar a presença de matriz extracelular, fato não constatado no GB.

Apesar da fácil obtenção, a quantidade de plaquetas e leucócitos no PRP é um fator a ser considerado, uma vez que ainda há uma grande discussão na literatura sobre as concentrações ideais a serem aplicadas. Existem diversas formas de obtenção do PRP, dentre métodos manuais a automatizados, que refletem em composições diversas de fração proteica, leucócitos, hemácias e plaquetas (Kon et al 2013). As concentrações adequadas de plaquetas variam de oito vezes a concentração sanguínea basal até $200 \%$ a mais que a concentração sanguínea periférica (Marx 2001, Kon et al. 2013). No PRP utilizado nesse trabalho foi desprezada a zona de névoa. A retirada da fração que contém os leucócitos diminui a possibilidade de reações inflamatórias adversas, a produção exacerbada de citocinas próinflamatórias e o acentuado influxo celular (Yamada et al. 2012).

Observamos que a concentração de plaquetas deste estudo foi apropriada e tem sido empregada de acordo com a literatura (Schnabel et al. 2007, Textor et al. 2014, Moraes et al. 2015). Não há estudos padronizados na literatura que comparem a aplicação do PRP, com diferentes concentrações de plaquetas e leucócitos no tratamento de lesões condrais, em equinos, em relação à qualidade de reparação, potencial imunogênico ou inflamatório do tratamento, composição celular e molecular do líquido sinovial. Observamos apenas estudos analisando as diferentes repostas celulares e moleculares de articulações saudáveis após a aplicação do PRP, na presença ou não de CTMs (Dhar et al. 2015, Moraes et al. 2015). Dragoo et al. (2014) relataram que o PRP rico em leucócitos e hemácias demonstraram ser citotóxico para sinoviócitos em humanos, além de serem capazes de ativar a inflamação através da liberação de IL-1, TNF- $\alpha$ e IL-6, e Lee et al. (2013) relataram que o excesso de PRP poderia levar a formação de fibrose. Moraes et al. (2015) igualmente relataram reação inflamatória transitória após a aplicação de PRP em articulações saudáveis. No presente estudo não foi observada resposta inflamatória clínica após a utilização do PRP, assim como igualmente, não foram observadas relações entre a formação de fibrose e sua utilização, ressaltando ainda que a zona de névoa, aqui, foi descartada.

O PRP foi capaz de suportar o implante conjunto de CTMs, sem alterar suas capacidades de gelificação, se tornando um arcabouço estável e bem aderido no local da lesão condral induzida. Essa associação melhorou a qualidade do tecido de reparação, pela ação conjunta das vantagens apresentadas pela utilização das CTMs, como quimiotaxia, imunomodulação, proliferação e migração, somadas ao suporte e à alta concentração de fatores de crescimento presentes no PRP, que estimulam a produção de matriz extracelular e a diferenciação condrogênica (Yamada 2011, Lee et al. 2013, Textor et al. 2014, Xie et al. 2014). Entendemos que, ainda são necessários estudos adicionais, principalmente objetivando a analise da viabilidade das CTMs no interior desse bioarcabouço, tempo exato de duração no local do implante e concentração adequada de fatores de crescimento que esse composto deve apresentar. Já é sabido que em estruturas tridimensionais há uma alteração da viabilidade celular, de acordo com o metabolismo apresentado pela célula (Farrell et al. 2012), assim como, a presença exacerbada de VEGF, presente em abundância no PRP, pode levar à apoptose de condrócitos (Mifune et al. 2013). 


\section{CONCLUSÕES}

$\mathrm{O}$ arcabouço de PRP em gel demonstrou boa viabilidade de aplicação cirúrgica, sendo de fácil manuseio. A sua aplicação suportou o implante das CTMs e preencheu adequadamente o defeito condral.

As lesões tratadas com CTM em gel de PRP apresentaram um tecido de reparação com melhor aspecto morfológico macroscópico e microscópico.

O tratamento de CTMs incorporadas no arcabouço de PRP demonstrou ser promissor no tratamento de lesões condrais, devendo ser explorado detalhadamente.

\section{Agradecimentos.- FAPESP (Proc. 2011/19705-9 e 2012/03600-6).}

\section{REFERÊNCIAS}

Beitzel K., McCarthy M.B., Cote M.P., Russell R.P., Apostolakos J., Ramos D.M., Sangamesh G.K., Andreas B.I., Robert A.A. \& Mazzocca A.D. 2014. Properties of biologic scaffolds and their response to mesenchymal stem cells. Arthroscopy 30:289-298.

Dhar M., Amelse L., Neilsen N., Favi P. \& Carter-Arnold J. 2015. Platelet-Rich Plasma Enhances the Cellular Function of Equine Bone Marrow-Derived Mesenchymal Stem Cells. Journal of Stem Cell Research \& Therapy. <http://dx.doi.org/10.4172/2157-7633.1000278>

Dragoo J.L., Wasterlain A.S., Braun H.J. \& Nead K.T. 2014. Platelet-rich plasma as a treatment for patellar tendinopathy: a double-blind, randomized controlled trial. Am. J. Sports Med. 42(3):610-618.

Farrell M.J., Farrell K.M., Riggin C.N. \& Mauck R.L. 2012. Mesenchymal stem cell death in three-dimensional agarose culture for cartilage tissue engineering applications: progression, factors, and prevention. 38th Annual Northeast Bioengineering Conference (NEBEC), Temple University, Philadelphia, PA, p.117-118.

Jain P., Jain R., Jain A.K., Jindal M. \& Dixit R. 2012. Autologous platelet gel and its clinical application. Natl J. Integr. Res. Med. 3:164-168.

Kon E., Filardo G., Di Matteo B., Perdisa F. \& Marcacci M. 2013. PRP-augmented scaffolds for cartilage regeneration: a systematic review. Oper. Tech. Sports Med. 21:108-115.

Kon E., Buda R., Filardo G., Di Martino A., Timoncini A., Cenacchi A., Fornasari P.M., Giannini S. \& Marcacci M. 2010. Platelet-rich plasma: intra-articular knee injections produced favorable results on degenerative cartilage lesions. Knee Surg. Sports Traumatol. Arthrosc. 18:472-479.

Krüger J.P., Hondke S., Endres M., Pruss A., Siclari A. \& Kaps C. 2012. Human platelet-rich plasma stimulates migration and chondrogenic differentiation of human subchondral progenitor cells. J. Orthop. Res. 30:845-852.

Lee J.C., Min H.J., Park H.J., Lee S., Seong S.C. \& Lee M.C. 2013. Synovial membrane-derived mesenchymal stem cells supported by platelet-rich plasma can repair osteochondral defects in a rabbit model. Arthroscopy 29:1034-1046.

Marx R.E. 2001. Platelet-rich plasma (PRP): what is PRP and what is not PRP? Implant Dent. 10:225-228.

Mcllwraith C.W. 2005. Diagnostic and Surgical Arthroscopy in the Horse. 3rd ed. Mosby-Elsevier, Edinburgh. 479p.

Mifune Y., Matsumoto T., Takayama K., Ota S., Li H., Meszaros L.B., Usas A., Nagamune K., Gharaibeh B., Fu F.H. \& Huard J. 2013. The effect of platelet-rich plasma on the regenerative therapy of muscle derived stem cells for articular cartilage repair. Osteoarthr. Cartil. 21:175-185.
Milano G., Sanna Passino E., Deriu L., Careddu G., Manunta L., Manunta A., Saccomanno M.F. \& Fabbriciani C. 2010. The effect of platelet rich plasma combined with microfractures on the treatment of chondral defects: an experimental study in a sheep model. Osteoarthr. Cartil. 18:971-980.

Moraes A.P., Moreira J.J., Brossi P.M., Machado T.S., Michelacci Y.M. \& Baccarin R.Y. 2015. Short-and long-term effects of platelet-rich plasma upon healthy equine joints: Clinical and laboratory aspects. Can. Vet. J., La Revue Veterinaire Canadienne, 56:831-838.

Pichereau F., Décory M. \& Ramos G.C. 2014. Autologous platelet concentrate as a treatment for horses with refractory fetlock osteoarthritis. J. Equine Vet. Sci. 34:489-493.

Schnabel L.V., Mohammed H.O., Miller B.J., McDermott W.G., Jacobson M.S., Santangelo K.S. \& Fortier L.A. 2007. Platelet rich plasma (PRP) enhances anabolic gene expression patterns in flexor digitorum superficialis tendons. J. Orthop. Res. 25:230-240.

Sun Y., Feng Y., Zhang C.Q., Chen S.B. \& Cheng X.G. 2010. The regenerative effect of platelet-rich plasma on healing in large osteochondral defects. Int. Orthop. 34:589-597.

Textor J.A., Norris J.W. \& Tablin F. 2011. Effects of preparation method, shear force, and exposure to collagen on release of growth factors from equine platelet-rich plasma. Am. J. Vet. Res. 72:271-278.

Textor J.A. \& Tablin F. 2012. Activation of equine platelet-rich plasma: comparison of methods and characterization of equine autologous thrombin. Vet. Surg. 41:784-794.

Textor J.A., Murphy K.C., Leach J.K. \& Tablin F. 2014. Ultrastructure and growth factor content of equine platelet-rich fibrin gels. Am. J. Vet. Res. 75:392-401.

Textor J.A. \& Tablin F. 2013. Intra-articular use of a platelet-rich product in normal horses: clinical signs and cytologic responses. Vet. Surg. 42:499510.

Tsuzuki N., Seo J.P., Yamada K., Haneda S., Furuoka H., Tabata Y. \& Sasaki N. 2013. The effect of a gelatin $\beta$-tricalcium phosphate sponge loaded with mesenchymal stem cells (MSC), bone morphogenic protein-2, and platelet-rich plasma (PRP) on equine articular cartilage defect. Can. Vet. J. 54:573.

Xie X., Wang Y., Zhao C., Guo S., Liu S., Jia W. \& Zhang C. 2012. Comparative evaluation of MSCs from bone marrow and adipose tissue seeded in PRP-derived scaffold for cartilage regeneration. Biomaterials 33:70087018.

Xie X., Zhang C. \& Tuan R.S. 2014. Biology of platelet-rich plasma and its clinical application in cartilage repair. Arthritis Res. Ther. 16:204.

Yamada A.L.M. 2011. Efeito do implante autólogo de plasma rico em plaquetas (PRP) e células tronco mesenquimais na reparação de lesões condrais articulares induzidas experimentalmente em equinos. Dissertação de Mestrado, Faculdade de Medicina Veterinária e Zootecnia, Universidade Estadual Paulista, Botucatu, SP. 111p.

Yamada A.L.M., Carvalho A.M.D., Oliveira P.G.G., Felisbino S.L., Queiroz D.L., Watanabe M.J., Hussni C.A. \& Alves A.L.G. 2012. Plasma rico em plaquetas no tratamento de lesões condrais articulares induzidas experimentalmente em equinos: avaliação clínica, macroscópica, histológica e histoquímica. Arq. Bras. Med. Vet. Zootec. 64:318-322.

Yamada A.L.M., Mattos Carvalho A., Moroz A., Deffune E., Watanabe M.J., Hussni C.A., Rodrigues C.A. \& Alves A.L.G. 2013. Mesenchymal stem cell enhances chondral defects healing in horses. Stem Cell Discov. 3(4):218-225.

Zhu Y., Yuan M., Meng H.Y., Wang A.Y., Guo Q.Y., Wang Y. \& Peng J. 2013. Basic science and clinical application of platelet-rich plasma for cartilage defects and osteoarthritis: a review. Osteoarthr. Cartil. 21:1627-1637. 